\title{
Erratum to: Reassessment of the Morphology and Taxonomic Status of the Earliest Herpetotheriid Marsupials of Europe
}

\author{
Sandrine Ladevèze • Richard Smith • Thierry Smith
}

(C) Springer Science+Business Media, LLC 2012

\section{Erratum to: J Mammal Evol DOI 10.1007/s10914-012-9195-0}

The original version of this article unfortunately contained mistakes, due to a rearrangement of two figures that was not followed by a modification of the captions.

Figure 5: The M4 (Da-b) was initially in the $\mathbf{H}$ position. When moved to $\mathbf{D}$ position, the captions should have been moved one rank forward. Therefore, the captions should be corrected by the following:

D IRSNB-M-2043 (DIIC-1118-RS), right M4; E IRSNB-M-2039 (DIIC-1229-RS), right M2; F IRSNBM-2040 (DIII-134-S), left M2; G IRSNB-M-2041 (DIIC-2031-RS), left M3; H IRSNB-M-2042 (DIIC1331-RS), left M3.

Figure 7: inversion of $\mathbf{e}$ and $\mathbf{d}$, captions should be corrected by the following:

d MNHN-RZN-28, right m2-4 (reversed); e MNHNRZN-31, left m2-3

Consequent to these two figure rearrangements, the text should be corrected in three places:

The online version of the original article can be found at http://dx.doi.org/ 10.1007/s10914-012-9195-0.

S. Ladevèze $(\bowtie) \cdot R$. Smith $\cdot$ T. Smith

Department of Paleontology,

Royal Belgian Institute of Natural Sciences,

29 rue Vautier, 1000 Brussels, Belgium

e-mail: ladeveze@mnhn.fr

Present Address:

S. Ladevèze

UMR 7207 CNRS (CR2P), USM 203,

Département Histoire de la Terre,

Muséum national d'Histoire naturelle,

CP38, 8, rue Buffon, 75231 Paris cedex 05, France
1) just under Figure 6, the sentence "In some specimens, the paracone is as tall as the metacone (e.g., IRSNB-M2042, Fig. 5g)." should be corrected as follows:

"In some specimens, the paracone is as tall as the metacone (e.g., IRSNB-M-2041, Fig. 5g).”

2) again under Figure 6, the sentence "...blistered with a strong angulation of the labial part of the crown (e.g., IRSNBM-2041, Fig. 5f, or..." should be corrected as follows:

““.... blistered with a strong angulation of the labial part of the crown (e.g., IRSNB-M-2040, Fig. 5f, or...”

3 ) in the paragraph describing the Study Of the Morphological Variability, the sentence "Two specimens exhibit a large stylar area, with a paracone that is as tall as the metacone (Fig. 5f-g)." should be corrected as follows:

"Two specimens exhibit a large stylar area, with a paracone that is as tall as the metacone (Fig. $5 \mathrm{~g}-\mathrm{h}$ )."

Moreover, two typing errors remained in the text and must be corrected by the following:

- Abstract, line 11: "hepertotheriid lineages" (instead of "hepetotheriid lineages")

- Page 11, line 6: "A. brabantense" (instead of " $A$. brabatense") 